\title{
Distensión abdominal en paciente con derivación ventriculoperitoneal
}

\author{
Abdominal distension in a patient \\ with ventriculoperitoneal shunt
}

\author{
Katia Solís-Díaz, Gloria Alonso-Claudio, Pilar Benito-García, Ignacio Novo-Veleiro \\ Servicio de Medicina Interna. Hospital Clínico Universitario de Salamanca.
}

\begin{abstract}
Resumen
Se presenta el caso de un paciente varón de 27 años con antecedentes de derivación ventriculoperitoneal desde la infancia que consulta por distensión abdominal de tres meses de evolución y fiebre, sin otra clínica asociada. Se realiza una paracentesis diagnóstica con datos de exudado y una ecografía y TAC abdominal que muestran un pseudoquiste abdominal, sin datos de infección. Se decide la extirpación quirúrgica del mismo y la recolocación del catéter a nivel suprahepático, con desaparición de la ascitis. En la evolución presenta disfunción del sistema por obstrucción, por lo que se recambia la derivación, con buena evolución posterior.

El pseudoquiste es una complicación rara pero grave de la derivación ventriculoperitoneal. Puede producir clínica abdominal, neurológica 0 infecciosa. El diagnóstico se realiza fundamentalmente por ecografía y TAC abdominal y el tratamiento aconsejado es la evacuación quirúrgica junto con resección de la cápsula y la recolocación del drenaje.
\end{abstract}

PALABRAS CLAVE: Pseudoquiste, derivación ventriculoperitoneal, líquido cefalorraquídeo, ascitis, distensión abdominal

El pseudoquiste es una complicación poco frecuente de la derivación ventriculoperitoneal de patogenia no aclarada que, en el caso que presentamos apareció tras varios episodios de recambio de catéter por disfunción del sistema y probablemente debido a irritación peritoneal crónica.

\section{Caso clínico}

Varón de 27 años que consultó por aumento progresivo del perímetro abdominal de tres meses de evolución. Como antecedentes era portador de una derivación ventriculoperitoneal que se implantó a los tres meses de edad por estenosis del acueducto de Silvio, secundaria a meningitis por Listeria. Precisó en dos ocasiones recambio de catéter por disfunción, la última dos años atrás. A la exploración física el paciente estaba febril, pero mantenía un buen estado general, sin signos de sepsis, el abdomen era globuloso, con semiología ascítica y no presentaba signos de hipertensión endocraneal. En la analítica el hemograma era normal, y destacaba una proteína C reactiva de $20,74 \mathrm{mg} / \mathrm{dL}$, sin leucocitosis y con una velocidad de sedimentación globular (VSG) de $87 \mathrm{~mm} / \mathrm{h}$. Se realizó una ecografía abdominal que confirmaba la presencia de ascitis abundante.Se extrajeron hemocultivos, que fueron negativos. Se realizó una paracentesis diagnóstica que mostraba un líquido seroso, compatible con exudado (glucosa $66 \mathrm{mg} / \mathrm{dL}$, lactato deshi-

\begin{abstract}
We report a case of a 27 year old male with a history of ventriculoperitoneal shunt in childhood consulting for abdominal distension and fever of three months's duration without other associated symptoms. Diagnostic paracentesis is performed with data from exudate and abdominal ultrasound and CT abdomen showing a pseudocyst without evidence of infection. It was decided the surgical removal of the pseudocyst and the reposition of the catheter at the suprahepatic location, with disappearance of ascites. Later, he had system dysfunction because of obstruction, so the derivation was exchanged with good outcome. The pseudocyst is a rare but serious complication of ventriculoperitoneal shunt. May cause abdominal clinical, neurological or infectious. The diagnosis is mainly done by ultrasound and abdominal CT scan and the recommended treatment is surgical removal with resection of the capsule and the relocation of drainage.
\end{abstract}

KEYWORDS: Pseudocyst, ventriculoperitoneal shunt, cerebroespinal fluid, ascites, abdominal distension

drogenasa de $265 \mathrm{U} / \mathrm{L}$, proteínas 3,20 g/dL, 455 leucocitos/mm3, $84 \%$ polimorfonucleares). La adenosin deaminasa era normal, los cultivos para bacterias y micobacterias fueron negativos y la citología, negativa para células malignas.

Tras la obtención de cultivos del líquido y en espera de recibir el resultado de los mismos, se inició tratamiento antibiótico empírico con meropenem y vancomicina, con disminución de la fiebre; se realizó un TAC craneal, en la que no había signos de dilatación ventricular y una TAC abdominal (figura 1) que mostraba gran cantidad de ascitis rodeada de membrana, compatible con un pseudoquiste. Junto con neurocirugía y cirugía general se decide la extirpación del mismo por laparotomía (figura 2) y la recolocación del catéter a nivel suprahepático. El paciente evoluciona favorablemente, por lo que se da de alta. Acude a Urgencias una semana más tarde por cefalea, ingresando en neurocirugía por disfunción valvular, se procede al recambio del catéter y de la válvula, que se recoloca a nivel atrial. El diagnóstico final fue el de pseudoquiste peritoneal secundario a irritación peritoneal crónica por catéter.

\section{Discusión}

La derivación ventriculoperitoneal (DVP) es el método más usado y efectivo para el tratamiento de las hidrocefalias ${ }^{1-4,6}$, sobre todo en la infancia. Se basa en un juego de presiones 
Figura 1

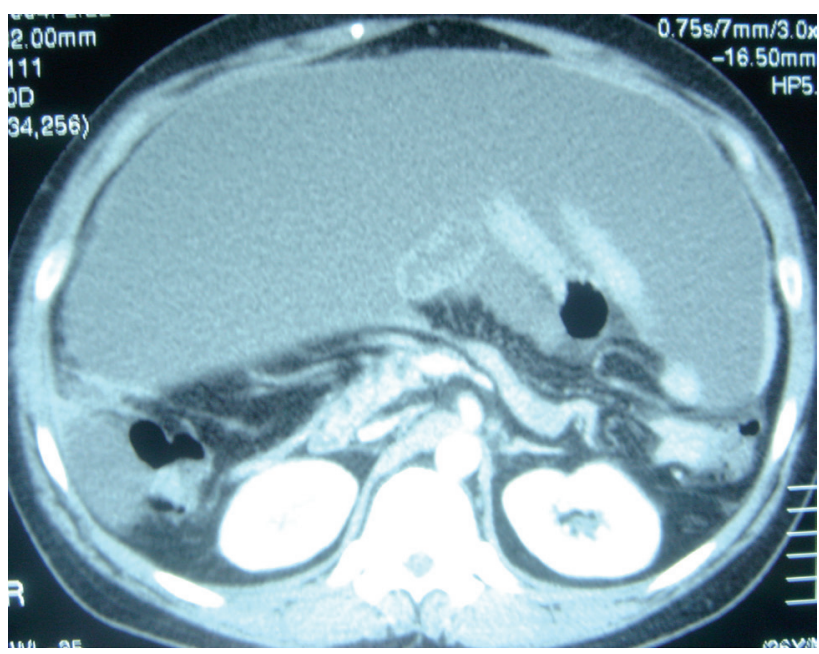

en el que la válvula se abre cuando la presión intracraneal sobrepasa a la presión intraabdominal².

Presenta numerosas complicaciones entre las que destacan la disfunción valvular con hidrocefalia, hemorragia (intracraneal 0 abdominal), lesión nerviosa, migración del catéter, infección, oclusión y perforación intestinal, pseudoquiste abdominal, pseudotumor mesentérico o peritonitis ${ }^{2,4-6}$.

El pseudoquiste abdominal es un acúmulo de líquido cefalorraquídeo (LCR) rodeado de tejido fibroso sin revestimiento epitelial (en el caso de existir éste se considera un quiste) $)^{1,3-4}$.
Es una complicación rara, con una incidencia normalmente de menos del $1 \%{ }^{1,5}$, pero una de las más importantes por el riesgo de hipertensión endocraneal que conlleva ${ }^{1}$.

La patogenia no es bien conocida, existen factores predisponentes para su desarrollo, como la inflamación crónica, las adherencias peritoneales, el aumento de proteínas del LCR, la obstrucción del catéter distal y las múltiples revisiones y recambios de los shunts ${ }^{1,3-6}$. La infección se considera la principal causa de desarrollo del pseudoquiste en ausencia de signos sistémicos de infección ${ }^{1,3}$. Los principales causantes son S.aureus, S.epidermidis y la flora bacteriana abdominal ${ }^{1}$. El origen infeccioso es más propio de los pseudoquistes de pequeño tamaño o multiloculados, los de gran tamaño suelen ser estériles ${ }^{3-5}$.

Se manifiesta con síntomas abdominales, como dolor, distensión, efecto masa, náuseas o vómitos y neurológicos con signos de hipertensión intracraneal, disminución del nivel de conciencia y focalidad ${ }^{1,4-5}$. La clínica abdominal suele preceder a la neurológica, y puede presentarse hasta diez años después de la colocación de la DVP³ . Los niños presentan más sintomatología de hipertensión intracraneal y los adultos abdomina ${ }^{3,5}$. En el caso de asociar infección del catéter, aparecería fiebre, mal estado general y signos locales de infección ${ }^{1}$. La radiografía abdominal puede mostrar una masa, desplazamiento de vísceras o signos de obstrucción intestinal. Pero el diagnóstico se realiza principalmente con la ecografía y el

Figura 2

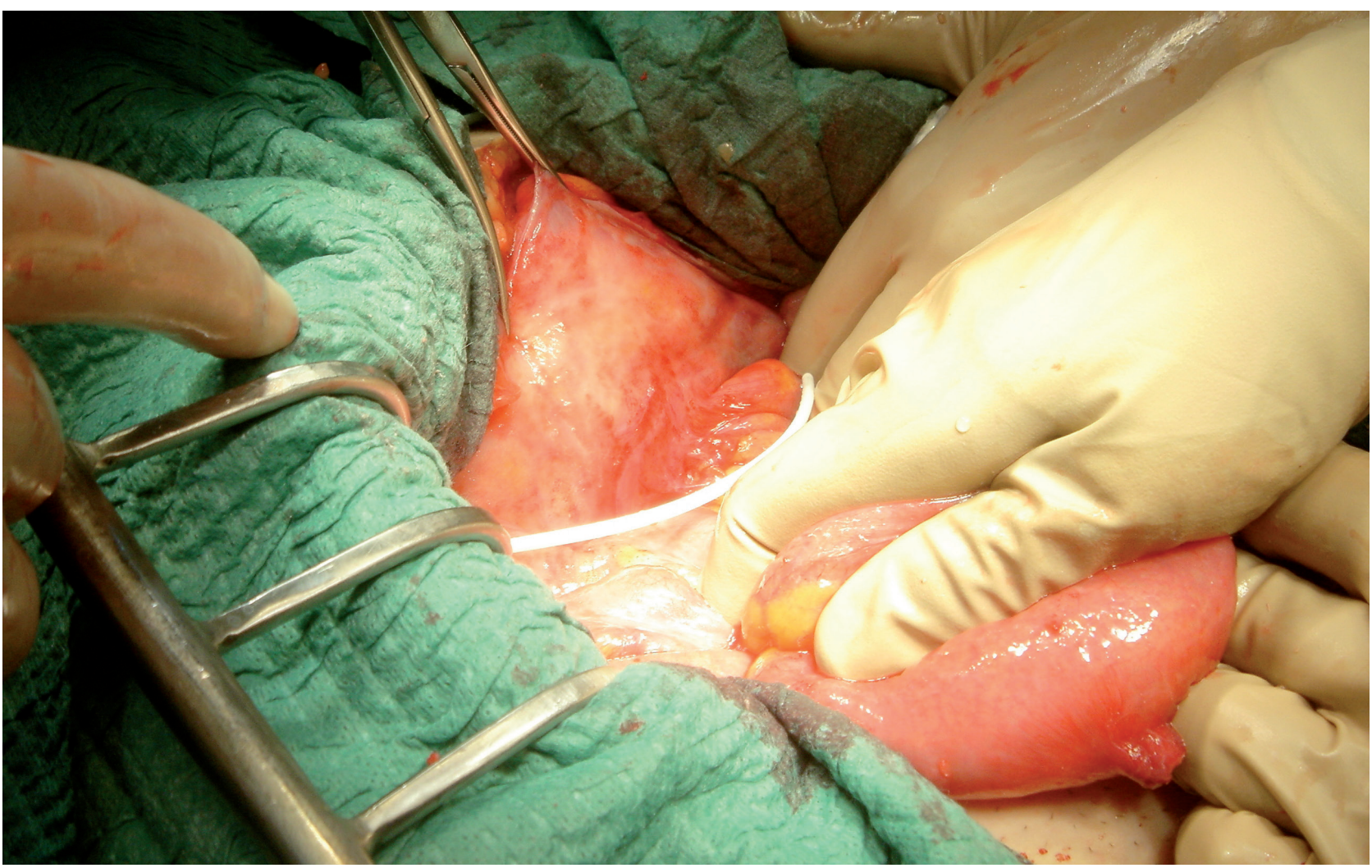


Figura 3

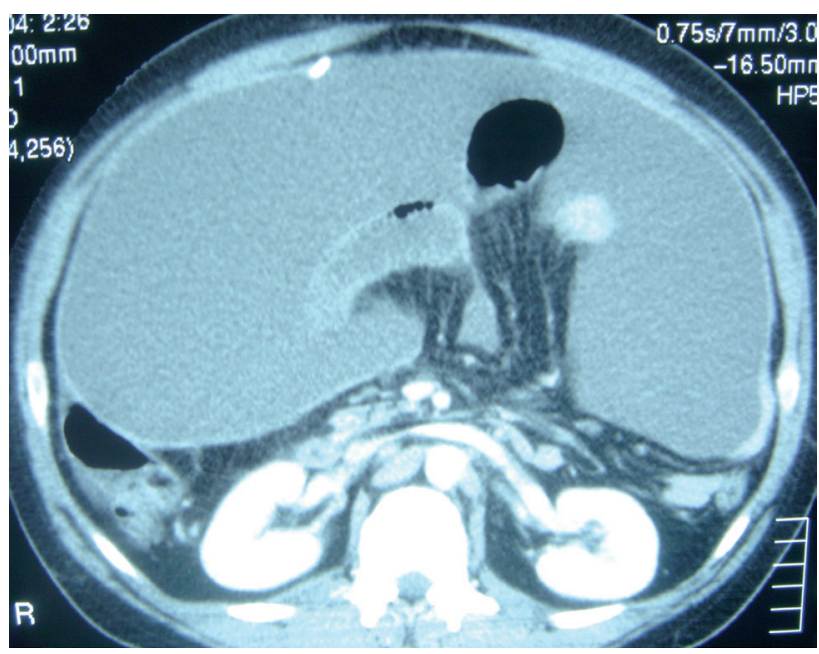

TAC abdominal1 1,35 (figura 3). La inyección de radioisótopos y la laparotomía diagnóstica también pueden ser útiles ${ }^{1,4}$. Entre los diagnósticos diferenciales se encuentran el quiste de mesenterio, la duplicación del intestino delgado y el absceso abdominal ${ }^{3-5}$. Es importante diferenciar el pseudoquiste, en el que la colección de LCR aparece alrededor de la punta del catéter, de la desconexión de la derivación, que suele darse junto a la conexión proximal y el LCR aparece en el tejido celular subcutáneo ${ }^{\top}$

En cuanto al tratamiento, la aspiración y la paracentesis quedan limitadas a colecciones accesibles y de escaso tamaño ${ }^{1}$. Lo más aceptado es la evacuación quirúrgica del líquido junto con la resección de la cápsula4 ${ }^{4}$. Existen varias opciones respecto a la actuación con el drenaje. En los distintos estudios no se ha llegado a un consenso, pudiéndose dejar in situ, cambiarlo a contralateral o suprahepático (de elección), 0 derivarlo a nivel atrial ${ }^{6}$, pleural 0 incluso al exterior ${ }^{1,3}$. En los casos en que aparezcan signos de infección, se aconseja retirar el catéter, cubrir con la antibioterapia adecuada, dejar el drenaje al exterior, y en cuanto se resuelva el cuadro, derivar nuevamente al peritoneo ${ }^{1,3}$; pero en algunos casos únicamente se racambia el sistema y se recoloca a nivel suprahepático 0 atrial, sin abocarlo al exterior temporalmente, pero siempre con la cobertura antibiótica adecuada.

En el caso de nuestro paciente, el pseudoquiste se presentó con sintomatología local (distensión abdominal) y sistémica (fiebre mantenida con buen estado general), sin síntomas neurológicos asociados. En la exploración el abdomen presentaba semiología ascítica sin signos locales de infección. En la analítica sólo destacaba la elevación de reactantes inflamatorios. Tras extraer cultivos de sangre y del líquido se inició antibioticoterapia empírica de amplio espectro, sin aislamiento microbiológico, atribuyendo la fiebre al proceso inflamatorio causado por la irritación peritoneal crónica, por lo que en la primera ocasión se recolocó el catéter sin recambio del mismo, que posteriormente hubo que realizar ante la disfunción del sistema.

\section{Bibliografía}

1. Martin Franco MA, Olabe J, López A, Vidal P, Soro JA. Quiste gigante de LCR como complicación en paciente con derivación ventriculoperitoneal. Revista Digital de Neurocirugía. [revista en internet] 2001. Enero. [acceso el 17 de febrero 2009]; [aprox 6 págs]. Disponible en: www.neurovia.org/700/retencion/retencion.htm

2. Sales Llopis J. Derivación ventriculoperitoneal. [consultado 13/03/2009]. Disponible en http:// www.neurocirugia.com/intervenciones/dvp/dvp.htm

3. Aguirre Rivero R, Pérez Salcedo C, Meza Martínez H, Kuri Guinto J, Vázquez Cruz I. Seudoquiste abdominal gigante en pacientes con derivación ventriculoperitoneal Rev. Gastroenterol Mex. 1998; 63 (3): 153-58

4. Aparici Robles F, Molina Fábrega R. Abdominal cerebroespinal fluid pseudocyst: a complication of ventriculoperitoneal shunts in adults. Journal of Medical Imaging and Radiation Oncology. 2008; 52: 40-43

5. Molina Fábrega R, Aparici Robles F, La Parra Casado C. Giant abdominal cerebroespinal fluid pseudocyst: an uncommon cause of acute abdomen. European Journal of Radiology Extra. 2006; 58: 69-72

6. Yukinaka M, Nomura M, Mitani T, Kondo Y, Tabata T, Nakaya Y, et al. Cerebroespina ascites developed 3 years after ventriculoperitoneal shunting in a hydrocephalic patient. Internal Medicine. 1998; 37: 638-41 